\title{
A polarity in European research
}

Lennart Philipson

\section{The large Human Capital and Mobility programme may at first sight seem like good news for European scientists. But this is far from the case.}

THE European Commission has recently launched a major fellowship programme, called Human Capital and Mobility, that could easily interfere with and even jeopardize other, similar European programmes directed by European scientific organizations. The total amount of money available for the Human Capital and Mobility programme is around 340 million ECU ( $\$ 428$ million), which compares, for example, with around 6 million ECU per year spent by the European Molecular Biology Organization (EMBO) for its fellowships. One consequence of this vast capital investment is that the stipends from the European Commission are much higher than those from organizations like EMBO: the amount paid for an European Commission postdoctoral stipend is more comparable to a professor's salary than to that of a postdoctoral fellow.

The European Commission has made assurances that the scientific standards of this programme should be high and rigidly adhered to during the assessment of applications, but the application and the peer-review procedures would surely be considered a parody by anyone outside the system. A major fraction of the funds in the first round was reserved for fellowships to so-called centres of excellence, yet these applications had to be submitted within two weeks of receipt of the application forms. The space available on these forms allowed only a summary presentation of the project, and no specific questions were asked about the selection procedure for the fellows which, of course, has to be very stringent to ensure the highest quality.

\section{Inconsistencies}

The peer-review committee for the Commission's fellowships, consisting of scientists of high reputation, was not allowed to evaluate the proposals independently, but its members were asked to come to Brussels for several days to read and comment on the proposals. Several of these scientists could not stay for more than a single day and the final allotment of funds seems to indicate that the committee has drizzled support over as many centres as possible instead of identifying a few top ones. The European Commission is obviously again confusing two different intentions: what it needs to do is to develop a system for awarding separate types of support to developing and élite science centres.

As things stand, after passing this initial scrutiny, each selected centre had to rewrite its application in a contract form, now taking into account the bureaucratic rules of the Commission that were not mentioned in the original application forms. These rules may make it impossible for some centres to accept the money they have been awarded.

Next, and most important, this massive influx of fellowship support may very well lead to reluctance on the part of some European governments to provide funds for fellowships to European organizations like EMBO or the Human Frontier Science Program. Even the small amount of money provided for research through other, smaller European organizations may be jeopardized when the resources are compared with those provided by the Commission. It is understandable that European governments, which pay through different channels for all these European activities, feel that fellowship funds in Europe must soon become saturated because of this massive influx from the Commission. It would be a tragedy if support for these existing European programmes begins to fall away, because the selection of fellows through a reliable peer-review system and the flexibility in providing funds is much better in several of these smaller programmes.

Although additional resources for scientific training and mobility in Europe are always welcome, this latest example of the European Commission's idiosyncrasy appears to establish, after numerous similar incidents in the past, that correction of the system can hardly be achieved from within the organization. It obviously does not realize it is sick.

Representing an organization independent of the Commission, I propose an alternative mechanism to assure support both for the Commission and its competing European institutions before Europe becomes locked in a centralized, fossilized policy. Each of the current 12 member states of the European Commission should pay a contribution to the Commission consisting of at least $1 \%$ of collected value-added tax and in addition $90 \%$ of the import duty on goods imported from outside the European Communities. All this may in the future amount to up to $1 \%$ of the gross national product of the individual member states.
This major contribution must, of course, be based on a well-controlled income declaration which must be negotiated between Brussels and the governments of the member states.

\section{Survival}

To ensure that alternative European programmes survive and receive adequate support despite these gigantic transfers to Brussels, a simple solution would be that the Council of Ministers which, after all, if unanimous, is the body determining the Commission's policy, requests that all the costs for joint European activities should be deductible from the income-tax return to Brussels in the same way as an individual taxpayer may deduct expenses incurred for earning the income. With this system, the European Commission's budget would probably be affected very little. This system would also certainly improve national resources for basic science within member states. The European programmes would furthermore be better coordinated with the Commission's activities, since the same national agency would probably be in charge of both the payment to Brussels as well as the deduction from this payment. It would probably take only one meeting at the prime-ministerial level to ensure that science programmes at least operate with a decentralized, functional system instead of a bureaucratic, inflexible European Commission policy.

Therefore, with a single move one can establish two important principles: first, that European initiatives are not competing with each other for funds but are allowed to develop in a decentralized fashion; and second, that these different activities are compared with regard to quality, cost-effectiveness and administrative efficiency as they would be evaluated by the same agencies at national levels. After all, Europeans can afford to test out several different procedures to achieve first-class science. It is high time that we reorganize European science to regain the leading role that Europe has had in the past.

Lennart Philipson is Director-General of the European Molecular Biology Laboratory, Meyerhofstrasse 1, 6900 Heidelberg, Germany. The opinion expressed in this commentary is personal and does not reflect the official position of EMBO or EMBL. 